\title{
Retinal vascular occlusion as a presenting feature of glaucoma simplex
}

\author{
K. G. SONI AND D. F. WOODHOUSE \\ Wolverhampton and Midland Counties Eye Infirmary
}

The purpose of this study has been to assess the frequency with which chronic simple glaucoma presents in an outpatient clinic as some type of retinal accident and also the significance of the association.

Although it is generally accepted that a thrombotic glaucoma can complicate a central retinal venous occlusion, the frequency of retinal venous occlusion occurring in eyes with established glaucoma simplex seems less well known, even though this was first described by Verhoeff (1913) and has been emphasized by Duke-Elder and Jay (1969). Some recent authors (Becker and Post, I951 ; Higgitt, I956; Dryden, I965; Tarkkanen, Raitta, and Vannas, I967) have mentioned the relationship between simple glaucoma and central retinal venous occlusion, although Raitta (1965) postulated that tributary venous occlusion was no commoner in simple glaucoma than in comparable age groups of the general population.

It seemed to us that it would be useful to assess the extent of this relationship of simple glaucoma to retinal vascular occlusion using the improved diagnostic methods now available, especially applanation tonometry and electronic tonography.

\section{Aetiology of retinal vascular occlusion in glaucoma}

The factors contributing to retinal vascular occlusion have been discussed by DukeElder and Dobree (1967); these include defective arterial flow, stagnation of the circulation, degenerative and inflammatory vascular disease, and glaucoma. It is most likely that glaucoma acts by producing circulatory stagnation as demonstrated by Moses (1963) in studies on the relationship of intraocular pressure to vascular flow using a hydrodynamic model eye. Moses showed that the flattening of the rubber tube (the vessel) was at first localized to the "venous" end, but that, as the "intraocular" pressure was increased further, the flattening extended towards the "arterial" end. It is therefore also likely that in the human eye glaucoma would affect the area of the central retinal vein, where vascular pressure is lowest.

However, since the incidence of both vascular disease and glaucoma simplex increase with age, it is probable that vascular changes also participate in the aetiology of occlusion.

\section{Methods of present study}

The clinical material of this study consisted of the patients referred to the glaucoma clinic of this hospital for investigation following a retinal vascular accident during the period 1967 to 1969 . Of the 727 patients referred during this period, glaucoma was not confirmed in 86 . 
The intraocular pressure was measured by a Goldmann applanation tonometer on the 900 slit lamp, and this is also the routine method used in the outpatient clinics. The tonography was performed using a Schwartzer electronic tonometer and recorder, the results being processed by an ICT I 500 computer at the Birmingham Regional Board by a method previously reported (Woodhouse, 1969).

\section{Clinical details and results}

Of the 727 patients referred, 25 had had a retinal vascular occlusion and the clinical details of twenty with confirmed glaucoma are summarized in Table I. It should be noted that in five patients with a vascular occlusion glaucoma was not confirmed, and that two patients had had bilateral venous occlusion at the onset of their symptoms. All patients had open drainage angles.

Table I Clinical details of twenty patients with confirmed glaucoma in the eye affected by vascular occlusion

\begin{tabular}{|c|c|c|c|c|c|c|}
\hline \multirow{2}{*}{$\begin{array}{l}\text { Type of retinal } \\
\text { vascular occlusion } \\
\text { (with confirmed } \\
\text { glaucoma) }\end{array}$} & \multicolumn{2}{|c|}{ Number of patients } & \multicolumn{4}{|c|}{ Average values for each group } \\
\hline & Male & Female & Age (yrs) & Intraocular pressure & Outflow facility $\left(C_{\boldsymbol{e}}\right)$ & $P / c$ \\
\hline Central vein & Io & 5 & 60 & 28 & $0 \cdot 22$ & 127 \\
\hline Tributary vein & 3 & I & 62 & 24 & 0.17 & 140 \\
\hline Central artery & I & & 50 & 22 & $0 \cdot 10$ & 220 \\
\hline
\end{tabular}

Table II shows the incidence of glaucoma in relation to the total number of patients attending with retinal vascular accidents and indicates the visual results after treatment.

Table II Incidence of glaucoma and retinal vascular occlusion in 3 years

\begin{tabular}{|c|c|c|c|c|c|c|c|c|}
\hline \multirow[b]{2}{*}{$\begin{array}{l}\text { Type of retinal } \\
\text { vascular occlusion }\end{array}$} & \multicolumn{3}{|c|}{$\begin{array}{l}\text { New patients attending hospital during } \\
3 \text { years }\end{array}$} & \multicolumn{2}{|c|}{ Treatment of cases referred } & \multicolumn{3}{|c|}{ Visual result (acuity, field) } \\
\hline & $\begin{array}{l}\text { Total with a } \\
\text { retinal } \\
\text { vascular } \\
\text { occlusion }\end{array}$ & $\begin{array}{l}\text { Total } \\
\text { referred to } \\
\text { glaucoma } \\
\text { clinic }\end{array}$ & $\begin{array}{l}\text { Total eyes } \\
\text { with } \\
\text { glaucoma }\end{array}$ & $\begin{array}{l}\text { Total eyes } \\
\text { controlled } \\
\text { (pressure } \\
<21 \mathrm{~mm} . \mathrm{Hg} \text { ) }\end{array}$ & $\begin{array}{l}\text { Total with } \\
\text { anti- } \\
\text { coagulants }\end{array}$ & Improved & $\begin{array}{l}\text { No significant } \\
\text { change }\end{array}$ & Deteriorated \\
\hline Central vein & 64 & 20 & 15 & II & 6 & 4 & 9 & 2 \\
\hline Tributary vein & 35 & 4 & 5 & 4 & $\mathbf{I}$ & 3 & 2 & \\
\hline Central artery & 40 & $\mathbf{I}$ & I & $\mathbf{I}$ & & $\mathbf{I}$ & & \\
\hline Total & 139 & 25 & 21 & 16 & 7 & 8 & II & 2 \\
\hline
\end{tabular}

\section{Discussion of the results of 3-year survey}

\section{(I) DIAGNOSIS}

The diagnosis of glaucoma in retinal venous occlusion may be easily missed if the possibility of glaucoma is not suspected, as the increase in intraocular pressure is often small. In our series the average intraocular pressure was $27 \mathrm{~mm}$.Hg when first measured (range 17 to 50). However, tonography has been useful in the diagnosis of borderline cases and the average coefficient of facility of aqueous outflow (Ce) was $0.2 \mathrm{~mm} .3 / \mathrm{min} . / \mathrm{mm}$ as compared with $0.3^{8}$ for eyes in which glaucoma had been excluded. 
The importance of the examination of the contralateral eye must be stressed, since failure to diagnose glaucoma in this eye may lead to loss of visual function either through a second vascular occlusion or through progressive glaucomatous optic atrophy. In our series fifteen patients had evidence of glaucoma in the contralateral eye, and nine of these showed a higher intraocular pressure in this eye than in that with vascular occlusion at the first attendance. It seems probable that the intraocular pressure of the eye affected by retinal venous occlusion is more unstable, and this has been confirmed by repeated measurements of the pressure (applanation phasing).

(2) INCIDENGE AND AETIOLOGIGAL FAGTORS

Of the 64I patients attending with a confirmed diagnosis of chronic simple glaucoma, twenty (3.I per cent.) had presented with an acute visual disturbance due to a retinal vascular accident. Although this is only a small percentage of the total group of glaucoma patients, it does represent 14.4 per cent. of the total group of retinal vascular occlusions attending during the same period. If venous occlusions are considered separately, the percentage rises to 25 per cent. for central vein occlusion, but falls to 8.6 per cent. for tributary vein occlusion. It would therefore seem that glaucoma is a significant feature in the aetiology of venous occlusion, and we would advise the investigation of every case for glaucoma, including a routine applanation tonometry of both eyes at the first visit.

The incidence of primary glaucoma in this series $(25$ per cent. for central vein occlusion and 8.6 per cent. for tributary vein occlusion) is fairly close to estimates in previous series. Raitta ( 1965 ) examined $25^{8}$ patients with retinal venous occlusion occurring over a period of 14 years and reported an incidence of 28 per cent. for central vein occlusion, but commented that the incidence of glaucoma in tributary vein occlusion was equivalent to that in the general population aged 65 years and over. However, in our series, fourteen of the twenty patients were less than 65 years old. Dryden (1965) showed an incidence of glaucoma in 19 per cent. of eyes with central vein occlusion and in 69 per cent. for the opposite eyes; this study was partly histological, which may have produced a higher incidence of advanced cases.

There was a preponderance of males in our series ( 13 out of 20), which reflects the higher incidence of vascular disease in males.

\section{（3） TREATMENT}

The routine treatment for retinal venous occlusion has been anticoagulation, using drugs such as warfarin or phenindione, but this treatment has often proved unsuccessful and is also not without dangers of internal haemorrhage, especially in the older patient. In the present series anticoagulants were given only to the younger patients and those with an occlusion affecting a large area of the retina; those who were treated with anticoagulants did not progress significantly better and, out of six, two retained a visual acuity of less than $6 / 60$, two improved, and two with an acuity of better than 6/1 2 retained it.

Of those patients with confirmed glaucoma in the eye affected by vascular occlusion (20 in the present series), fourteen were controlled by treatment with miotic eye drops, and acetazolamide as necessary, and two with surgery. In these patients the intraocular pressure had remained satisfactory for periods of $\mathrm{I}$ to 3 years, but the visual acuity and visual field have shown significant improvement in only eight (two of whom had anticoagulants also). Although this is not a dramatic result, we feel that it justifies the careful control of glaucoma in all such cases, since long-term prognosis of neglected glaucoma simplex is so poor, even without retinal vascular occlusion. 


\section{Summary}

The aetiology, incidence, and treatment of simple glaucoma in retınovascular occlusion are discussed in relation to a clinical series. 25 per cent. of patients with central retinal venous occlusion had glaucoma, but only 8.6 per cent. of those with tributary venous occlusion. It is emphasized that the diagnosis of simple glaucoma should be considered in all patients presenting as a retinal vascular accident.

\section{References}

BECKER, B., and POST, L. т. (1951) Amer. F. Ophthal., 34, 677

DRYDEN, R. M. (1965) Arch. Ophthal. (Chicago), 73, 659

DUKE-ELDER, S., and DOBREE, J. H. (1967) "System of Ophthalmology", vol. ı, p. 98. Kimpton, London and JAY, B. (1969) Idem, vol. I I, p. 668. Kimpton, London

HigGitT, A. G. (1956) Trans. ophthal. Soc. U.K., 76, 73

MOSES, R. A. (1963) Ophthalmologica (Basel), 146, 137

RAITTA, C. (1965) Acta ophthal. (Kbh.), Suppl. 83

sCheIE, H. G. (1957) A.M.A. Arch. Ophthal., 58, 5 Io

TARKKanen, A., Raitta, C., and vannas, s. (1967) v. Graefes Arch. Ophthal., 171, 307

VERHOEFF, F. H. (1913) Arch. Ophthal. (N.Y.), 42, 145

woodhouse, D. (1969) Exp. Eye Res., 8, 127 